\title{
Simultaneous Determination of the Free and Total Carbamazepine Concentrations in Human Plasma by High-Performance Frontal Analysis Using an Internal-Surface Reversed-Phase Silica Support
}

\author{
Akimasa Shibukawa, ${ }^{*}$ Naohiro Nishimura, Kayoko Nomura, Yoshihiro Kuroda and Terumichi Nakagawa \\ Faculty of Pharmaceutical Sciences, Kyoto University, Yoshidashimoadachi-cho, Sakyo-ku, Kyoto 606, Japan. Received June 13, 1989
}

\begin{abstract}
High-performance frontal analysis (HPFA) was applied to simultaneous determinations of the free and total carbamazepine (CBZ) concentrations in human plasma. When $1.5 \mathrm{ml}$ of human plasma containing $\mathrm{CBZ}$ at a clinical therapeutic level (free fraction, about $30 \%$ ) was directly injected into an internal-surface reversed-phase silica column, the $\mathrm{CBZ}$ was separated from the plasma blank and was eluted as a zonal peak with a plateau height corresponding to the free CBZ concentration in protein binding equilibrium. Slow and continuous introduction of the plasma sample and the use of titanium filters permitted us to inject the sample repeatedly while avoiding a rapid increase in column pressure. The free and total CBZ concentrations were determined simultaneously from the peak height at the plateau region and the area of the $\mathrm{CBZ}$ peak, respectively. The within-run and day-to-day reproducibilities were satisfactory $(\mathrm{C} . \mathrm{V} . \leq 1.63 \%$, $n=5)$.
\end{abstract}

Keywords protein binding; internal-surface reversed-phase silica column; high performance liquid chromatography; albumin; carbamazepine

It is well known that drugs in the blood are bound more or less to plasma proteins such as albumin and $\alpha_{1}$-acid glycoprotein, and that an equilibrium exists between the concentrations of bound and free forms. Only the free drug is considered to diffuse from the blood to the extravascular site of drug action and to exhibit a pharmacological activity or side-effects. Determination of not only the total drug concentration but also the free drug concentration is thus significant from the standpoint of therapeutic drug monitoring. ${ }^{1,2)}$ In particular, to monitor the free drug concentration in the plasma is indispensable in chemotherapy with drugs whose therapeutic levels of the free forms lie within a narrow range and are changeable, such as phenytoin and disopyramide. The ultrafiltration method has so far been employed exclusively for this purpose. ${ }^{3)}$ This method involves two distinct operations: ultrafiltration of a plasma sample by the use of a disposable ultrafiltration kit, and determination of the drug concentration in the filtrate usually by high performance liquid chromatography (HPLC). In addition, this method has the potential defect that the drug might be adsorbed partly on the membrane of the filter, and the bound drug might leak out because of a break in the membrane. In addition, the total drug concentration cannot be determined without additional experiments after releasing bound drugs from the proteins. The disposable ultrafiltration kit is also expensive. It is of practical value therefore to establish a method which permits us to determine the free and total drug concentrations simultaneously with a single direct injection of a plasma sample without pre-treatment.

In a previous paper, ${ }^{4}$ we developed a high-performance frontal analysis (HPFA) method, which enables the simple and rapid determination of the free drug concentration in protein binding equilibrium. In the HPFA method, the sample solution was applied continuously to an ISRP silica column. This silica support consists of a hydrophilic external surface and a moderately hydrophobic internal (pore) surface, and it size-excludes macromolecules such as plasma proteins but retains small molecules such as drugs in the pores. $^{4-14)}$ After sample injection, proteins were eluted at first, and the drug was then eluted as a zonal peak with a plateau. The free drug concentration could be determined directly from the plateau height of the peak, since they are in a linear relationship. This method does not suffer from the Donnan effect and undesirable drug adsorption often encountered in the equilibrium dialysis method and ultrafiltration method. The much smaller sample volume (about $100 \mu \mathrm{l}-2 \mathrm{ml}$, depending on the free drug fraction) and shorter analysis time as compared with conventional gelfiltration frontal analysis ${ }^{15,16)}$ are also attractive from the practical standpoint. In addition, the HPFA method has the potential advantage that if the drug peak is separated completely from the protein peak, both the free and the total drug concentrations can be determined simultaneously from the peak height at the plateau region and the peak area of the drug, respectively. In the present study, we applied the HPFA method to determine both the free and total carbamazepine (CBZ) concentrations in human plasma. The therapeutic concentration range of $\mathrm{CBZ}$ in human plasma is very narrow $(4-12 \mu \mathrm{g} / \mathrm{ml}),{ }^{17)}$ and monitoring of the plasma concentration is therefore of clinical importance.

\section{Experimental}

Reagents and Materials Human serum albumin (HSA; fatty acid free) was purchased from Sigma (St. Louis, Mo.), and was dissolved in potassium phosphate buffer ( $\mathrm{pH} 7.4$, ionic strength $(I)=0.17$ ). The concentration of HSA was determined spectrophotometrically using the extinction coefficient $E_{1}^{1 \%} \mathrm{~cm}=5.31$ at $279 \mathrm{~nm}$. Sodium laurate of guaranteed reagent grade, purchased from Nacalai Tesque Inc. (Kyoto, Japan), was dissolved in the phosphate buffer ( $\mathrm{pH} 7.4, I=0.17)$. CBZ of guaranteed reagent grade was purchased from Wako Pure Chemicals (Osaka, Japan). Human plasma was prepared from fresh human blood in the usual manner. As ethanol solution of $10 \mathrm{~mm} \mathrm{CBZ}$ was spiked into human plasma and HSA solution or HSA-laurate mixed solution to prepare a sample containing $4-12 \mu \mathrm{g} / \mathrm{ml} \mathrm{CBZ}$. The sample solution was kept at $37^{\circ} \mathrm{C}$ until being subjected to HPFA or to ultrafiltration.

HPLC Conditions for HPFA Apparatus: A Tri Rotar III system (Jasco, Japan) equipped with a UV detector, SPD-2A (Shimadzu, Japan), and an integrated data analyzer, Chromatopac C-R3A (Shimadzu), was employed. A Rheodyne type 7125 injector with a $2-\mathrm{ml}$ or $5-\mathrm{ml}$ loop was used for sample injection.

Mobile Phase: Potassium phosphate buffer (pH 7.4, $I=0.17$ )

Flow Rate: $1.2 \mathrm{ml} / \mathrm{min}$ for CBZ-HSA mixed solutions; $0.1 \mathrm{ml} / \mathrm{min}(0-$ $50 \mathrm{~min}$ ) and $1.2 \mathrm{ml} / \mathrm{min}$ (after $50 \mathrm{~min}$ ) for human plasma samples.

Stationary Phase: An ISRP silica support (Regis Chemical Co., Morton Grove, IL) was purchased from Koken Co. (Tokyo, Japan). Column temperature: $37^{\circ} \mathrm{C}$, controlled in a water bath. 
Detection: UV, $300 \mathrm{~nm}$.

Determination of the Free Drug Concentration by Ultrafiltration Ultrafiltration using Molcut II (UFP1 LGC, Milipore Co.) was employed as a reference standard method to determine the free drug concentration. CBZ was not adsorbed on the ultrafiltration membrane. Each 200$\mu \mathrm{l}$ portion of the filtrate containing free drug was obtained by pressurizing $1 \mathrm{ml}$ of the sample solution. All filtration procedures were carried out at $37^{\circ} \mathrm{C}$. A $40-\mu$ l or $80-\mu$ l portion of the filtrate was subjected to reversed-phase HPLC to determine the free drug concentration. The HPLC conditions were as follows.

Stationary Phase: Chemcosorb 7ODSH $(15 \mathrm{~cm} \times 4.6 \mathrm{~mm}$ i.d., Chemco, Osaka).

Mobile Phase: $\mathrm{H}_{2} \mathrm{O}: \mathrm{MeOH}=1: 1$ for $\mathrm{CBZ}$. Flow rate: $1.5 \mathrm{ml} / \mathrm{min}$.

Detection: UV, $280 \mathrm{~nm}$.

\section{Results and Discussion}

Effect of Drug Displacement Interaction on HPFA It is well known that drugs bound to protein are often displaced by endogenous substances such as fatty acids and other drugs administered simultaneously, so that the free drug concentration becomes elevated. ${ }^{1,2)}$ It is of importance therefore to examine the drug displacement effect on the HPFA determination of the free drug concentration.

The displacement of CBZ by laurate adsorbed on HSA was taken as a model case, and two kinds of mixed solutions of CBZ $(8.00 \mu \mathrm{g} / \mathrm{ml})$ and HSA $(593 \mu \mathrm{M})$ with and without laurate $(600 \mu \mathrm{M})$ were prepared. The free $\mathrm{CBZ}$ concentrations determined previously by the ultrafiltration method were 2.62 and $2.02 \mu \mathrm{g} / \mathrm{ml}$ for the above solutions with and without laurate, respectively. Evidently, the displacement of the drug from protein by the laurate raised the free CBZ concentration by 1.3 -fold.

These solutions were subjected directly to a commercially available ISRP silica column $(15 \mathrm{~cm} \times 4.6 \mathrm{~mm}$ i.d. $)$ at a flow rate of $1.2 \mathrm{ml} / \mathrm{min}$ without connecting a guard column. No increase in column pressure was noted during this experiment.

Figures $1 \mathrm{~A}$ and $1 \mathrm{~B}$ show the chromatograms obtained by the HPFA of a CBZ-HSA mixed solution and of that containing laurate, respectively. After HSA was sizeexcluded, $\mathrm{CBZ}$ was eluted as a zonal peak with a plateau range. The shape of the $\mathrm{CBZ}$ peak was quite different from that obtained from an aqueous CBZ solution of the same concentration $(8 \mu \mathrm{g} / \mathrm{ml})$ injected at the same volume (Fig. 1C). The chromatogram of a $2-\mathrm{ml}$ portion of the $8 \mu \mathrm{g} / \mathrm{ml}$ CBZ- $600 \mu \mathrm{m}$ laurate mixed solution was exactly the same as Fig. 1C (laurate was not detected at this wavelength

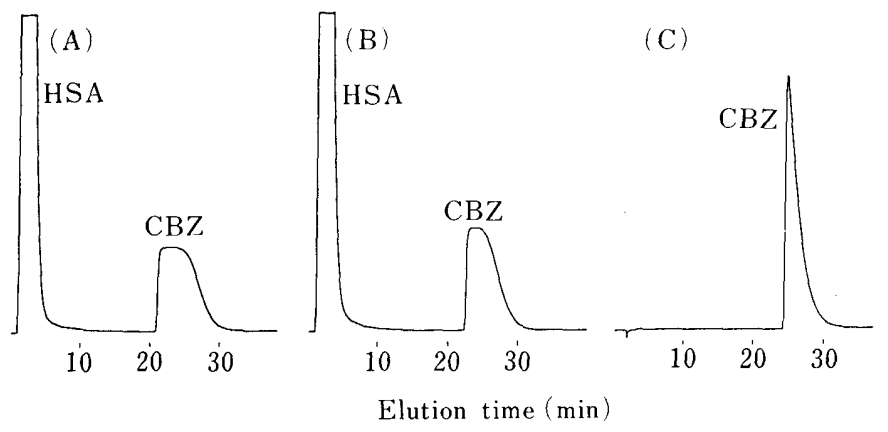

Fig. 1. HPFA of $8 \mu \mathrm{g} / \mathrm{ml} \mathrm{CBZ} \mathrm{in} \mathrm{Mixed} \mathrm{Solutions} \mathrm{of} \mathrm{(A)} 593 \mu \mathrm{M} \mathrm{HSA}$ and (B) $593 \mu \mathrm{M}$ HSA- $600 \mu \mathrm{m}$ Sodium Laurate, and (C) a Chromatogram of $8 \mu \mathrm{g} / \mathrm{ml} \mathrm{CBZ}$ in Buffer Solution

HPLC conditions: Stationary phase: Pinkerton column $(15 \mathrm{~cm} \times 4.6 \mathrm{~mm}$ i.d. $)$. Mobile phase: phosphate buffer ( $\mathrm{pH} 7.4, I=0.17$ ). Flow rate: $1.2 \mathrm{ml} / \mathrm{min}$. Detection: UV, $300 \mathrm{~nm}$. Injection volume: $2.0 \mathrm{ml}$. Column temperature: $37^{\circ} \mathrm{C}$.
$(300 \mathrm{~nm})$ ), which implies that laurate did not influence the shape of the CBZ peak.

The reason for this difference can be explained, taking into account the equilibria for the protein binding in the interstices of the ISRP silica particles and the retention of the drug on the stationary ligands. When a drug-protein mixed solution was injected into the ISRP silica column, the bound drug was released from the protein penetrating into the pores of the ISRP silica particles, and was retained on the stationary ligands as illustrated schematically in Fig. $2 \mathrm{~A}$. As a result, the binding condition in the mobile phase was quite different from that in the initial sample solution. When the sample injection continued, the concentration of the free drug tended to reach a steady state in a limited zone at the top of the column (Figs. 2B and 2C). In this zone (asterisked in Fig. 2C), the drug concentration in the mobile phase stagnant in the pores became equal to the free drug concentration in the mobile phase flowing through the interstices of the particles. Since the drug and the protein were in binding equilibrium in the interstices and the protein concentration was the same as that in the initial sample solution, the free drug concentration in the mobile phase was equal to that in the sample solution. That is, the continuous sample injection reproduced the same binding equilibrium in the mobile phase. In conventional frontal analysis, the sample injection continues until the free drug concentration reaches a steady state in the whole mobile phase. In HPFA, the sample injection ends when the steady state appears in a limited mobile phase at the top of the column. If the steady state zone is sufficiently long, the free drug in this zone is eluted as the zonal peak with a plateau, being separated from the protein. Accordingly, the peak height should correspond to the free drug concentration (Fig. 2D). Therefore, the plateau region in Figs. 1A and $1 \mathrm{~B}$

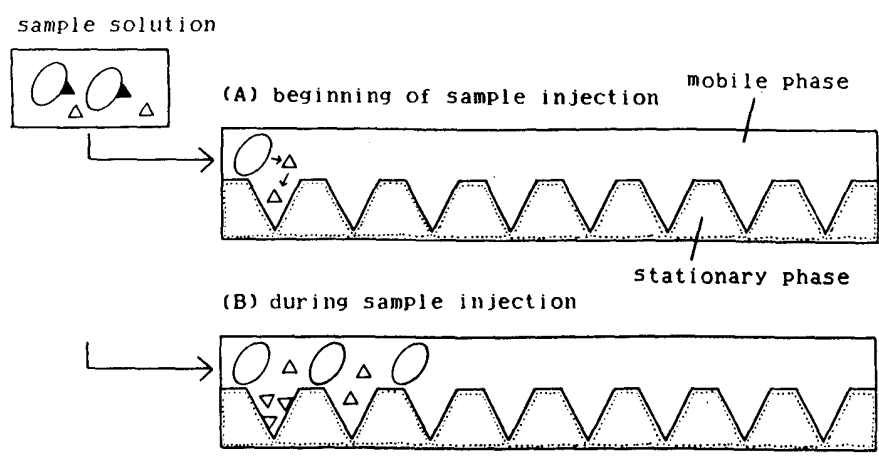

(C) end of sample injection

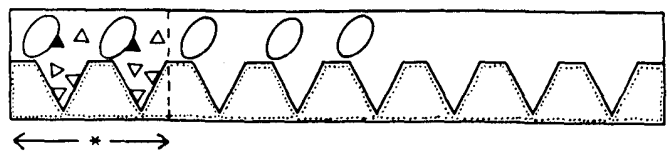

(D) after sample injection

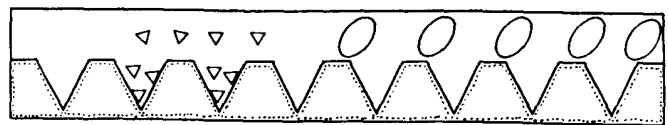

Fig. 2. Schematic Diagram of the HPFA Method

Asterisk: the steady state zone where the drug and protein are in the same binding equilibrium as that in the sample solution, and the drug concentration in the pores is equal to that of the free drug in the interstices of the ISRP silica particles. O, protein; $\Delta$, bound drug; $\triangle$, free drug. 
(A)

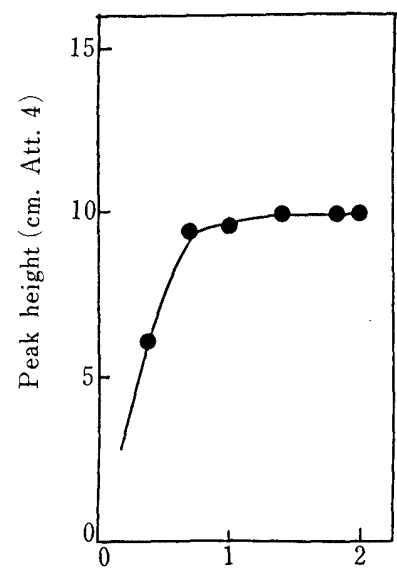

(B)

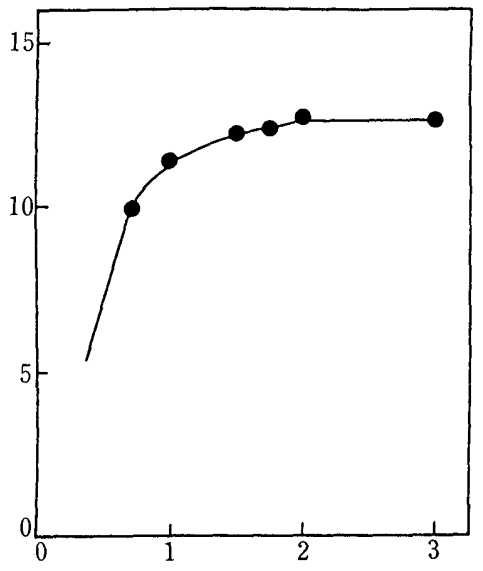

Injection volume $(\mathrm{ml})$

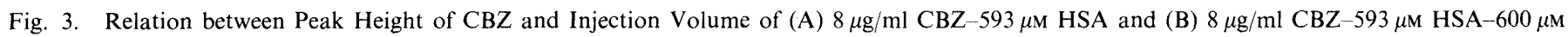
Sodium Laurate

Injection volume: $0.4-3.0 \mathrm{ml}$. Other HPLC conditions were the same as in Fig. 1.

TABLE I. Determination of the Total and Free CBZ Concentrations in $8.00 \mu \mathrm{g} / \mathrm{ml} \mathrm{CBZ}-593 \mu \mathrm{m}$ HSA Mixed Solution with and without $600 \mu \mathrm{M}$ Sodium Laurate

\begin{tabular}{ccccc}
\hline \multirow{2}{*}{ Sample } & \multicolumn{2}{c}{ HPFA } & & Ultrafiltration \\
\cline { 2 - 3 } \cline { 5 - 5 } & Free CBZ & Total CBZ & & Free CBZ $\mathrm{CBZ}^{a}$ \\
\hline \multirow{2}{*}{ Without laurate } & $1.92(\mu \mathrm{g} / \mathrm{ml})$ & $7.80(\mu \mathrm{g} / \mathrm{ml})$ & & $2.02(\mu \mathrm{g} / \mathrm{ml})$ \\
& $(2.80 \%)$ & $(2.72 \%)$ & & $(2.33 \%)$ \\
With laurate & 2.46 & 7.71 & & 2.62 \\
& $(3.33 \%)$ & $(3.90 \%)$ & & $(1.26 \%)$ \\
\hline
\end{tabular}

a) The free $\mathrm{CB} Z$ concentration determined by the ultrafiltration method. The values in parentheses indicate the coefficients of variation $(n=5)$. HPLC conditions. Stationary phase: Pinkerton column $(15 \mathrm{~cm} \times 4.6 \mathrm{~mm}$ i.d.). Mobile phase: phosphate buffer ( $\mathrm{pH} 7.4, I=0.17$ ). Detection: UV, $300 \mathrm{~nm}$. Flow rate: $1.2 \mathrm{ml} / \mathrm{min}$. Injection volume: $2.0 \mathrm{ml}$. Column temperature: $37^{\circ} \mathrm{C}$

could be due to the elution of free CBZ in this zone, and the plateau height should be ascribable to the free CBZ concentration in the initial plasma sample. This is the rationale of the present HPFA method, and the appearance of the plateau range of a drug peak is essential for determining the free drug concentration.

Figure 3 shows the relation between the injection volume and the peak height of CBZ. As the injection volume increased, so the peak reached a maximum height, and finally showed a plateau range. The asymptotic relation in Fig. 3B was not ascribable to laurate, since, as mentioned above, this substance did not influence the shape of the CBZ peak. The minimum injection volume (MIV) required to obtain a plateau range was different between Figs. 3A and $3 \mathrm{~B}$. The MIV of the sample without laurate was about $1.4 \mathrm{ml}$ (Fig. 3A), and that of the sample containing laurate was about $2.0 \mathrm{ml}$ (Fig. 3B). It is considered that the greater the free drug fraction in the sample solution, the greater is the amount of bound drug that should be released and enter the pores so as to attain a steady state concentration of the free drug. Thus, the large MIV in Fig. 3B can be attributed to the increase in the free CBZ fraction due to the displacement effect of laurate.

Table I lists the free and total CBZ concentrations determined for the mixed solutions of CBZ and HSA with and without laurate. The injection volume was $2.0 \mathrm{ml}$. The free CBZ concentrations calculated from the plateau height were $1.92 \mu \mathrm{g} / \mathrm{ml}$ (in the absence of laurate) and $2.46 \mu \mathrm{g} / \mathrm{ml}$ (in the presence of laurate). These values agreed with those determined by the ultrafiltration method (2.02 and 2.62 $\mu \mathrm{g} / \mathrm{ml}$, respectively). In addition, the total $\mathrm{CBZ}$ concentrations calculated from the $\mathrm{CBZ}$ peak area were 7.80 and $7.71 \mu \mathrm{g} / \mathrm{ml}$, and the recoveries of CBZ exceed $96 \%$. These results indicate that the bound CBZ molecules were completely released from the plasma proteins during their residence in the column, and eluted together with the free CBZ forming a zonal peak. Both the free and total CBZ concentrations can be therefore determined simultaneously by a single analysis, even when the drug displacement process is involved. The coefficient of variation was less than $3.90 \%(n=5)$ indicating good reproducibility.

Simultaneous Determination of the Free and Total CBZ Concentrations in Human Plasma by HPFA As mentioned above, the column pressure was rarely elevated by repeated injections of a mixed solution of the drug and purified serum albumin. However, repeated injection of $1.0-1.8 \mathrm{ml}$ of human plasma caused a rapid increase of the column pressure because of the adsorption of endogenous macromolecules onto the stainless-steel inlet frit. To avoid this, we employed titanium filters and a cartridge-type ISRP guard column $(1 \mathrm{~cm} \times 3 \mathrm{~mm}$ i.d., Koken Co. $)$. The flow rate of the mobile phase was $0.1 \mathrm{ml} / \mathrm{min}$ for the first $50 \mathrm{~min}$, and then was raised to $1.2 \mathrm{ml} / \mathrm{min}$. As a result, more than $50 \mathrm{ml}$ of plasma sample in total could be introduced into the column without any pressure elevation. Figure 4 presents chromatograms obtained by injection of different volumes of $4 \mu \mathrm{g} / \mathrm{ml} \mathrm{CBZ}$ in human plasma. The endogenous macromolecules such as plasma proteins were excluded during the first $50 \mathrm{~min}$. CBZ was eluted at about $66 \mathrm{~min}$ and was well separated from the plasma blank.

Figure 5 shows the relation between the injection volume of the plasma samples and the $\mathrm{CBZ}$ peak height. The CBZ concentrations of 4.00 and $12.0 \mu \mathrm{g} / \mathrm{ml}$ in these samples correspond to the lowest and highest limits of the thera- 
TABLE II. Determination of the Total and Free CBZ Concentrations in Human Plasma by HPFA

\begin{tabular}{|c|c|c|c|c|c|}
\hline \multirow{3}{*}{$\begin{array}{c}\mathrm{CBZ} \\
\text { added } \\
(\mu \mathrm{g} / \mathrm{ml})\end{array}$} & \multicolumn{4}{|c|}{ HPFA } & \multirow{3}{*}{$\begin{array}{c}\text { Ultrafiltration } \\
\begin{array}{c}\left.\text { Free CBZ conc. }^{a}\right) \\
(\mu \mathrm{g} / \mathrm{ml})\end{array}\end{array}$} \\
\hline & \multicolumn{2}{|c|}{ CBZ conc. $(\mu \mathrm{g} / \mathrm{ml})$} & \multicolumn{2}{|c|}{ Free CBZ conc. $(\mu \mathrm{g} / \mathrm{ml})$} & \\
\hline & (within-run) & (day-to-day) & (within-run) & (day-to-day) & \\
\hline \multirow[t]{2}{*}{4.00} & 3.93 & 3.97 & 1.10 & 1.09 & 1.15 \\
\hline & $(0.94 \%)$ & $(0.75 \%)$ & $(0.91 \%)$ & $(0.69 \%)$ & $(2.35 \%)$ \\
\hline \multirow[t]{2}{*}{12.0} & 11.9 & 11.8 & 3.32 & 3.31 & 3.64 \\
\hline & $(0.82 \%)$ & $(1.37 \%)$ & $(1.63 \%)$ & $(0.94 \%)$ & $(1.57 \%)$ \\
\hline
\end{tabular}

a) Determined by the ultrafiltration method (Molcut II, Millipore). The values in parentheses indicate the coefficients of variation ( $n=5$ ). HPLC conditions Stationary phase: Pinkerton column with titanium frits $(15 \mathrm{~cm} \times 4.6 \mathrm{~mm}$ i.d.). Guard column: cartridge-type Pinkerton column (1 $\mathrm{cm} \times 3 \mathrm{~mm}$ i.d.). Mobile phase: phosphate buffer ( $\mathrm{pH} 7.4, \mathrm{I}=0.17)$. Detection: $U V, 300 \mathrm{~nm}$. Flow rate: $0.1 \mathrm{ml} / \mathrm{min}(0-50 \mathrm{~min}), 1.2 \mathrm{ml} / \mathrm{min}$ (after $50 \mathrm{~min}$ ). Injection volume: $1.5 \mathrm{ml}$. Column temperature: $37^{\circ} \mathrm{C}$.
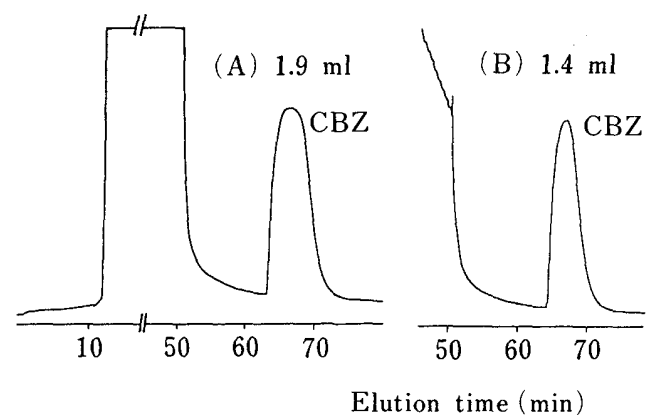

(C) $1.0 \mathrm{ml}$

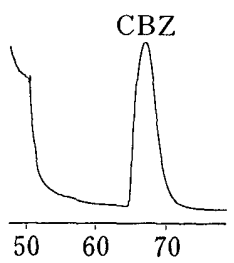

Elution time $(\min )$

Fig. 4. Chromatograms of $1.0-1.9 \mathrm{ml}$ of $4 \mu \mathrm{g} / \mathrm{ml} \mathrm{CBZ}$ in Human Plasma

HPLC conditions: Stationary phase; Pinkerton column with titanium frits $(15 \mathrm{~cm} \times 4.6 \mathrm{~mm}$ i.d.). Guard column: cartridge-type Pinkerton column ( $1 \mathrm{~cm} \times$

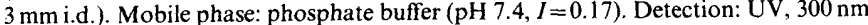
Flow rate: $0.1 \mathrm{ml} / \mathrm{min}(0-50 \mathrm{~min}), 1.2 \mathrm{ml} / \mathrm{min}$ (after $50 \mathrm{~min})$. Injection volume: $1.0,1.4,1.9 \mathrm{ml}$. Column temperature: $37^{\circ} \mathrm{C}$.

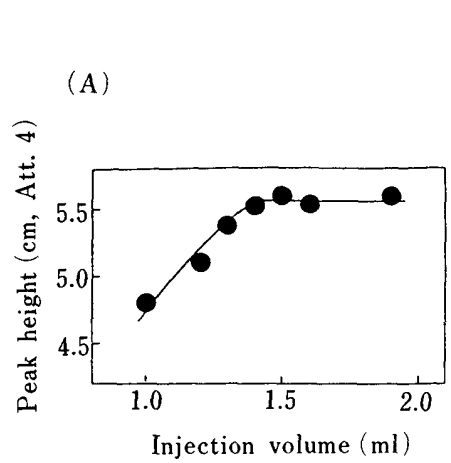

(B)

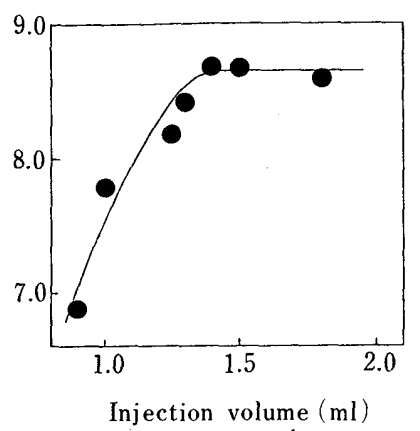

Fig. 5. Relation between Injection Volume of (A) $4 \mu \mathrm{g} / \mathrm{ml} \mathrm{CBZ}$ and (B) $12 \mu \mathrm{g} / \mathrm{ml} \mathrm{CBZ}$ in Human Plasma and the Peak Height of CBZ

Injection volume: $0.9-1.9 \mathrm{ml}$. Other HPLC conditions were the same as in Fig. 4.

peutic plasma concentration, respectively. The free $\mathrm{CBZ}$ fractions of these samples determined by the ultrafiltration method were $28.8 \%$ and $30.3 \%$, respectively. Injection of more than $1.4 \mathrm{ml}$ of each sample gave a maximum and plateau level of the CBZ peak.

Table II lists the assay values of the free and total CBZ concentrations and their within-run and day-to-day precisions $(n=5)$, where the injection volume was $1.5 \mathrm{ml}$. The CBZ concentration calculated from the peak height agreed well with the free CBZ concentration determined by the ultrafiltration method, and that calculated from the peak area agreed well with the total concentration of CBZ spiked into the plasma sample. The within-run and day-to-day coefficients of variation indicate a good reproducibility for the present method.

These results indicate the feasibility of the HPFA method for simultaneously determining the free and total $\mathrm{CBZ}$ concentrations in human plasma. It might be expected that further improvements could be focused on reducing the analysis time and injection volume. We found that a large guard column $(3 \mathrm{~cm} \times 4.6 \mathrm{~mm}$ i.d. $)$ permits repeated plasma injections under a moderate flow rate $(0.5 \mathrm{ml} / \mathrm{min})$ without increase of the column pressure. Selection of a guard column is thus effective for reducing the analysis time.

As mentioned earlier, the HPFA of the sample with a higher free drug fraction requires a larger injection volume. The $\%$ fraction of bound CBZ in clinical plasma samples is reported to be $70-80 \%{ }^{2}{ }^{2}$ The bound $\%$ in the plasma samples employed in this study $(71.2 \%$ and $69.7 \%)$ was near the lowest limit of the clinical levels. When the HPFA method is applied to the clinical monitoring of CBZ, it will rarely be the case that the injection volume exceeds that used in the present study $(1.5 \mathrm{ml})$, unless a considerable displacement effect occurs in the plasma. This sample volume $(1.5 \mathrm{ml})$, being larger than that employed for the ultrafiltration method $(0.5-1.0 \mathrm{ml})$, will be reduced by improvement of the column packing, since the diffusion of a drug in the column is an important factor to narrow the plateau region and hence to require a larger MIV value for the HPFA.

In principle, HPFA is applicable to any drug insofar as the drug-protein binding reaches equilibrium much faster than the chromatographic partition. When the release of bound drug is much slower than the chromatographic process, or a drug binds covalently to the plasma proteins, ${ }^{18)}$ the free drug will be easily separated from the proteins and bound drug by injecting a small volume of the sample solution into the ISRP silica column. For HPFA of a drug which shows a very high free fraction, a large volume of the sample solution must be injected. On the other hand, HPFA is particularly suitable when the protein binding is strong. For example, the free concentration of indomethacin in $550 \mu \mathrm{M}$ HSA solution (free fraction was $0.7 \%$ ) could be determined by injecting a sample solution of as little as $90 \mu \mathrm{l}^{4}{ }^{4}$ Furthermore, as mentioned, the HPFA method has the advantage that, the total and free drug concentrations can be determined simultaneously, insofar as the drug peak is separated completely from the protein peak.

\section{References}

1) T. C. Kwong, Clin. Chim. Acta, 151, 193 (1985). 
2) C. K. Svensson, M. N. Woodruff, J. G. Baxter and D. Lalka, Clin. Pharmacokinet., 11, 450 (1986).

3) E. H. Taylor and B. H. Ackerman, J. Liq. Chromatogr., 10, 323 (1987).

4) A. Shibukawa, T. Nakagawa, N. Nishimura, M. Miyake and H. Tanaka, Chem. Pharm. Bull., 37, 702 (1989).

5) I. H. Hagestam and T. C. Pinkerton, Anal. Chem., 57, 1757 (1985).

6) T. C. Pinkerton, T. D. Miller, S. E. Cook, J. A. Perry, J. D. Rateike and T. J. Szczerba, BioChromatography, 1, 96 (1986).

7) T. C. Pinkerton, J. A. Perry and J. D. Rateike, J. Chromatogr., 367, 412 (1986).

8) S. E. Cook and T. C. Pinkerton, J. Chromatogr., 368, 233 (1986).

9) T. Nakagawa, A. Shibukawa, N. Shimono, T. Kawashima H. Tanaka and J. Haginaka, J. Chromatogr., 420, 297 (1987).

10) A. Shibukawa, T. Nakagawa, M. Miyake and H. Tanaka, Chem.
Pharm. Bull., 36, 1930 (1988).

11) A. Shibukawa, T. Nakagawa, M. Miyake, N. Nishimura and H. Tanaka, Chem. Pharm. Bull., 37, 1311 (1989).

12) J. A. O. Meriluoto and J. E. Eriksson, J. Chromatogr., 438, 93 (1988).

13) R. H. Pullen, C. M. Kennedy and M. A. Curtis, J. Chromatogr., 434 271 (1988).

14) T. Ohshima, I. Johno, T. Hasegawa and S. Kitazawa, J. Liq. Chromatogr., 11, 3457 (1988).

15) G. C. Wood and P. F. Cooper, Chromatogr. Rev., 12, 88 (1970).

16) T. K. Korpela and J.-P. Himanen, "Aqueous Size-Exclusion Chromatography," Chapter 13, ed. by P. L. Dubin, Elsevier, 1988.

17) M. Gibaldi, "Biopharmaceutics and Clinical Pharmacokinetics," 3rd edition, Lea and Febiger, 1984, p. 161.

18) U. Kragh-Hansen, Pharmacol. Rev., 33, 17 (1981). 